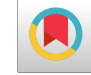

\title{
Are Cord Blood Bilirubin Values Trustable to Predict the Forthcoming Significant Hyperbilirubinemia Requiring Treatment in Healthy Term Newborns?
}

\author{
Bahareh Bahman Bijari ${ }^{1}$, Zahra Jamali ${ }^{2,{ }^{*}}$, Pedram Niknafs ${ }^{2}$, Elaheh Norouzi $^{3}$, Hamid Mosavi ${ }^{3}$, \\ Maryam Mohit ${ }^{4}$, Mohammad Reza Baneshi ${ }^{5}$, Zahra Shahriari ${ }^{6}$ and Habibeh Amiresmaeili ${ }^{6}$ \\ ${ }^{1}$ Kerman Physiology Research Center, Kerman Medical Sciences University, Kerman, Iran \\ ${ }^{2}$ Department of Pediatrics, Kerman Medical Sciences University, Kerman, Iran \\ ${ }^{3}$ Department of Pediatrics, Iran Medical Sciences University, Tehran, Iran \\ ${ }^{4}$ Department of Pathology, Kerman Medical Sciences University, Kerman, Iran \\ ${ }^{5}$ Biostatistics and Epidemiology Department, Research Center for Modeling in Health Institute, Kerman, Iran \\ ${ }^{6}$ Kerman Medical Sciences University, Kerman, Iran \\ "Corresponding author: Fellowship of Neonatology, Department of Pediatrics, Kerman Medical Sciences University, Kerman, Iran. Tel/Fax: +98-9124969707, Email: \\ zahra402@yahoo.com.au
}

Received 2017 September 24; Revised 2019 April 28; Accepted 2019 May 17.

\begin{abstract}
Background: Jaundice is a clinical condition that is often observed in pediatric practice and constitutes one of the major issues within the neonatal period. As severe jaundice causes neurotoxicity (kernicterus), the diagnosis and treatment of severe hyperbilirubinemia is very important. Early prediction will help in early discharge and will prevent hospitalization of babies and mothers. On the other hand, predicting outcome in high risk neonates for subsequent hyperbilirubinemia is required.

Objectives: This study investigates the predictive value of umbilical cord serum bilirubin (UCSB) for subsequent hyperbilirubinemia which is a required treatment in healthy term newborns.

Methods: In this prospective study, 238 healthy term newborns were inducted into the study. Soon after delivery, the cord blood was sent for serum bilirubin analysis. Newborns were followed up by TCB (transcutaneous bilirubinometry) until the third day post birth and those who showed significantly high TCB values, according to the hour-specific normogram, received the appropriate intervention and treatment. The data were analyzed using $t$-Test, ROC (receiver operating characteristic) curve, and chi-square tests. Results: Of 238 newborns, 27 (11.4\%) cases developed hyperbilirubinemia (bilirubin $\geq 15 \mathrm{mg} / \mathrm{dL}$ ), which required phototherapy. There were no significant differences between the cases who did and who did not develop hyperbilirubinemia (bilirubin $<15 \mathrm{mg} / \mathrm{dL}$ ) with respect to various factors that might be associated with the risk of hyperbilirubinemia such as mode of delivery and gender. However, two groups were significantly different in terms of cord bilirubin levels. ROC (receiver operating characteristic) analysis showed that the critical value of umbilical cord serum bilirubin (UCSB) $\geq 2.25 \mathrm{mg} / \mathrm{dl}$ had high sensitivity (92.6\%), good positive and negative predictive value (66\% and $69 \%$ respectively).

Conclusions: UCSB level $\geq 2.25 \mathrm{mg} / \mathrm{dL}$ can be a useful predictor of hyperbilirubinemia in healthy term newborns on the third day. Therefore, infants with UCSB level $\geq 2.25 \mathrm{mg} / \mathrm{dL}$ should be followed up strictly either in a hospital or in an outpatient department on the third day, whereas neonates with cord bilirubin level $<2.25 \mathrm{mg} / \mathrm{dL}$ are probably safe for early discharge.
\end{abstract}

Keywords: Hyperbilirubinemia, Newborns, Phototherapy, Jaundice

\section{Background}

Early hospital discharge is the most common cause of rehospitalization for jaundice (1) and is a risk factor for kernicterus $(2,3)$. Kernicterus (bilirubin encephalopathy) results from the deposition of unconjugated (indirect reacting) bilirubin in the basal ganglia and brainstem nuclei. It is also important to know that Kernicterus is an acquired metabolic encephalopathy in the neonatal period
(4). Early discharge of healthy term newborns within the first 48 hours of life is a common practice due to medical, social, and economic reasons (5). Owing to the early discharge as well as the development of hyperbilirubinemia in newborns, there is a lot of discussions and controversies in this regard (6). Consequently, recognition, follow up, and treatment of jaundice at early stages is difficult due to such discharge policies. We should be aware that ker- 
nicterus and severe jaundice can occur in some full-term healthy newborns that are discharged soon without clear, early findings of hemolysis (7). The American Academy of Pediatrics (AAP) suggests that newborns discharged within 48 hours should have a follow-up visit after 48 to 72 hours for any hyperbilirubinemia and other complications (8). This suggestion is impractical in Iran because of limited follow-up facilities as well as long distances to existing facilities.

Although our understanding concerning the physiological features of bilirubin and the mechanisms of bilirubin neurotoxicity has improved, our ability to make predictions to know which infants are at greatest risk remains limited. Predicting jaundice can be considered as an interesting tool to choose babies at risk of neonatal hyperbilirubinemia (9). It is difficult to make predictions concerning which infants are at increased risk for significant and relatively late hyperbilirubinemia. There is an obvious need to apply follow-up programs or to develop predictive guidelines that will enable physicians to predict or to identify which early discharged newborns will develop hyperbilirubinemia (10). Therefore, predicting the risk of jaundice for implementing the early treatment and consequently minimizing the risk of bilirubin-dependent brain damage is of salient importance.

\section{Objectives}

The objective of the present study was to find out the critical value of serum bilirubin in the cord blood in order to predict later development of hyperbilirubinemia in healthy term newborns up to their third day of life.

\section{Methods}

This prospective, cohort study was undertaken in the department of pediatrics at Afzalipour Hospital in Kerman, Iran. This study, conducted over a period of 9 months, was approved by the Ethics Committee of Kerman University of Medical Sciences. A total of 300 healthy newborns were included in the study. The inclusion criteria were: sequentially born term babies (gestational age $>37$ weeks) from any mode of delivery, both genders, birth weight above $2500 \mathrm{~g}$, Apgar score above 7 at first and fifth minutes of life, and without $\mathrm{ABO}$ and $\mathrm{Rh}$ incompatibility. The exclusion criteria were: babies who had major congenital malformations, Glucose-6-phosphate dehydrogenase deficiency, or birth asphyxia, NICU admitted babies due to severe illness or sepsis, cephalohematoma, prolonged rupture of membrane (more than 18 hours) and bruising. The gestational age was determined based on the findings of firsttrimester ultrasound (when available) or on account of the date of the last menstrual period. This was confirmed with the new Ballard score within 24 hours after birth. Two $\mathrm{ml}$ of cord blood were collected during delivery in two plain vials and were sent to the clinical laboratory of Afzalipour Hospital in order to determine the blood group and estimate the serum total, unconjugated, and conjugated bilirubin levels using a colorimetric method (Selectra XL, The Netherlands). Parents of all newborns were contacted and consent was obtained. The maternal blood group was obtained from medical records. The relevant history of mother and baby was taken and thorough physical and clinical examination of all neonates was performed. All recruited neonates were assessed clinically for the development of jaundice and other illnesses, every day, from birth until discharge by members of the medical team. Whenever necessary, further assessment for bilirubin level was done. The subjects were asked to return for follow-up after discharge at 72 hours of age or younger if parents found their baby icteric. The follow-up included clinical assessment and checking of bilirubin by transcutaneous bilirubinometry (TCB). TCB is a non-invasive method to measure bilirubin. It functions by directing white light into the skin and measures the intensity of the specific wavelengths returned. TCB measurement was done by JM-103 Jaundice Meter, Draeger medical AG \& Co, Lubeck, Germany. This measurement provides moderately accurate estimates of $\mathrm{TB}$ in term newborn infants with different races and ethnicities (11). Hyperbilirubinemia, which required therapy, was defined as TCB level of $15 \mathrm{mg} / \mathrm{dL}$ or more according to the percentile-based hour-specific transcutaneous bilirubin nomogram (12). If TCB was equal or more than 15 $\mathrm{mg} / \mathrm{dL}$, neonates were subjected to a serum venous bilirubin sample collection and appropriate intervention and treatment were then applied. The need for phototherapy was determined according to AAP2004 guidelines (11). Neonates who failed to return for follow-up were excluded from the study. We looked mainly for hyperbilirubinemia which needed phototherapy or exchange transfusion in healthy term newborns. Data were processed and analyzed using SPSS software for Windows version 20. Specificity, sensitivity, as well as negative and positive predictive value of four cut-points of cord bilirubin were obtained and the likelihood ratios of the test were calculated. Chi-square test, $t$-test and ROC curve were used whenever appropriate. P value $<0.05$ was considered as statistically significant.

\section{Results}

Of 300 infants who were enrolled into the study, 62 were excluded as they did not return or were not followed up. In addition, those who had a bad general condition (sepsis, respiratory distress, or heart failure) were 
excluded. All included newborns were from Kerman or nearby districts for easy referral to the hospital. A total of 238 (113 boys and 125 girls) healthy term newborns were inducted into the study. Of those, 112 (47\%) were born by vaginal delivery and 126 (53\%) by cesarian section. The predominant blood type among mothers and neonates was type $O$. Table 1 depicts the baseline characteristics of cases that developed and did not develop hyperbilirubinemia.

\begin{tabular}{|c|c|c|c|}
\hline Variable & $\begin{array}{l}\text { Hyperbilirubinemia } \\
\text { (TCB } \geq 15 \mathrm{mg} / \mathrm{dL} \text { ) } \\
\text { at } 72 \text { Hours of Life }\end{array}$ & $\begin{array}{c}\text { No Hyperbiliru- } \\
\text { binemia (TCB } \leq \\
15 \mathrm{mg} / \mathrm{dL} \text { ) at } 72 \\
\text { Hours of Life }\end{array}$ & PValue \\
\hline $\begin{array}{l}\text { Gender, } \\
\text { male/female }\end{array}$ & $16 / 11$ & $97 / 114$ & 0.193 \\
\hline Delivery, CS/NVD & $13 / 14$ & $114 / 98$ & 0.581 \\
\hline $\begin{array}{l}\text { Cord bilirubin } \\
(\mathrm{mg} / \mathrm{dL}), \text { mean } \pm \\
\text { SD }\end{array}$ & $3.11 \pm 0.72$ & $2.71 \pm 0.75$ & 0.010 \\
\hline $\begin{array}{l}\text { TCB at } 72 \text { hours of } \\
\text { life }(\mathrm{mg} / \mathrm{dL}) \text {, } \\
\text { mean } \pm S D\end{array}$ & $16.78 \pm 1.12$ & $10.56 \pm 2.87$ & 0.001 \\
\hline
\end{tabular}

The studied infants were categorized into two groups based on transcutaneous bilirubin level at 72 hours of age: 211 (88.6\%) neonates in group A who did not develop hyperbilirubinemia (TCB $<15 \mathrm{mg} / \mathrm{dL}$ ), and $27(11.4 \%)$ in group B who had hyperbilirubinemia (TCB $\geq 15 \mathrm{mg} / \mathrm{dL}$ ). In group $\mathrm{B}$, newborns, according to the hour-specific normogram, were admitted for appropriate intervention and treatment. All neonates in group B required phototherapy and none required exchange transfusion. There were no significant differences between groups A and B in terms of different factors that may be associated with the risk of hyperbilirubinemia such as gender $(\mathrm{P}=0.19)$ and type of delivery $(P=0.581)$. The mean $( \pm S D)$ of UCSB level within group $\mathrm{B}(3.11 \pm 0.72 \mathrm{mg} / \mathrm{dL})$ was significantly $(\mathrm{P}<$ $0.010)$ higher in comparison to that within group $\mathrm{A}(2.71$ $\pm 0.75 \mathrm{mg} / \mathrm{dL}$ ). Table 1 shows the baseline characteristics of cases that developed and did not develop hyperbilirubinemia. This table demonstrates that the mean ( \pm SD) of TCB level among the two groups was significantly different at 72 hours (16.78 \pm 1.12 in group B vs $10.56 \pm 2.87$ in group A) $(\mathrm{P}<0.001)$. Table 2 shows the relationship of serum bilirubin and cord bilirubin at 72 hours.

Of 182 newborns who had a UCSB level of $\geq 2.25 \mathrm{mg} / \mathrm{dL}$, 27 (11.4\%) developed hyperbilirubinemia which required treatment at 72 hours of life, whereas only two babies (7.2\%) who had UCSB $<2.25$ developed jaundice at 72 hours of age (Table 2). To identify a cut-off point of predicting a large number of babies at low risk of hyperbilirubinemia, an ROC curve was drawn (Figure 1).

\begin{tabular}{|c|c|c|c|}
\hline $\begin{array}{l}\text { Cord Bilirubin } \\
\text { Level, mg/dL }\end{array}$ & $\begin{array}{c}\text { Group A, TCB } \\
\text { Level } \leq 15 \mathrm{mg} / \mathrm{dL} \\
\quad(\mathrm{N}=\mathbf{2 1 2})^{\mathrm{a}}\end{array}$ & $\begin{array}{c}\text { Group B, TCB } \\
\text { Level } \geq 15 \mathrm{mg} / \mathrm{dL} \\
(\mathrm{N}=27)^{\mathrm{a}}\end{array}$ & P Value \\
\hline$\geq 2.25(\mathrm{~N}=182)$ & $157(74)$ & $25(92.6)$ & 0.033 \\
\hline$\leq 2.25(\mathrm{~N}=57)$ & $55(25)$ & $2(7.4)$ & \\
\hline
\end{tabular}

${ }^{\mathrm{a}}$ Values are expressed as No. (\%).

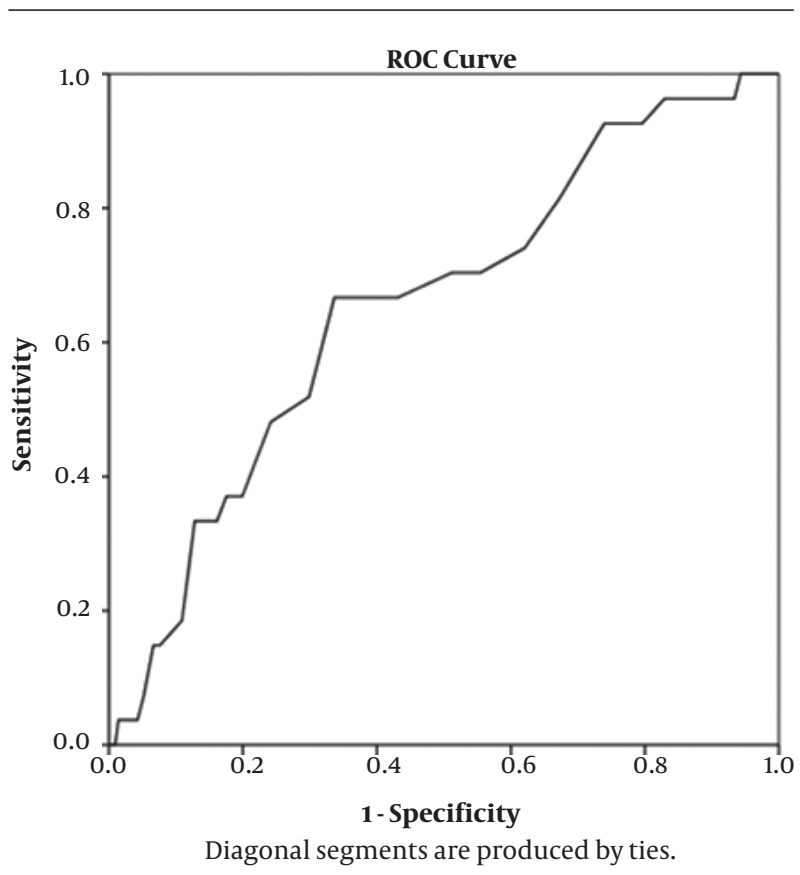

Figure 1. ROC curve analysis of cord blood bilirubin level at various cut off points

The ideal cut-off was $2.25 \mathrm{mg} / \mathrm{dL}$ as just two babies (7.2\%) below this level developed hyperbilirubinemia and $92.8 \%$ of jaundiced babies had UCSB levels above or equal to 2.25 $\mathrm{mg} / \mathrm{dl}$ (Table 3). The different cut-off points for UCSB levels and the specificity, sensitivity, as well as positive predictive value and negative predictive value for each cut-off point is depicted in Table 3.

Based on ROC curve analysis (Figure 1), a mean cord bilirubin level of $2.25 \mathrm{mg} / \mathrm{dL}$ had the highest sensitivity (92.6\%) to predict the neonates who would develop hyperbilirubinemia. At this critical mean cord bilirubin level, the positive predictive value was good (66\%), and negative predictive value was 69\%. At UCSB cut-off level of 2.99 $\mathrm{mg} / \mathrm{dL}$, the sensitivity and specificity was the same (66\%). 
Table 3. Cut Off Value of Umbilical Cord Serum Bilirubin and Its Sensitivity, Specificity, Positive Predictive Value, and Negative Predictive Value

\begin{tabular}{|c|c|c|c|}
\hline & \multicolumn{3}{|c|}{ Cut Off Value } \\
\hline & $2.25 \mathrm{mg} / \mathrm{dL}$ & $2.55 \mathrm{mg} / \mathrm{dL}$ & $2.99 \mathrm{mg} / \mathrm{dL}$ \\
\hline Sensitivity & $92.6 \%$ & $70 \%$ & $66 \%$ \\
\hline Specificity & $27 \%$ & $45 \%$ & $66 \%$ \\
\hline Positive predictive value & $67 \%$ & $65 \%$ & $75 \%$ \\
\hline Negative predictive value & $69 \%$ & $50 \%$ & $56 \%$ \\
\hline True positive & $55 \%$ & $42 \%$ & $39 \%$ \\
\hline False positive & $29 \%$ & $22 \%$ & $13.6 \%$ \\
\hline
\end{tabular}

\section{Discussion}

There is concern about the possibility of kernicterus and an increasing incidence of severe hyperbilirubinemia even in healthy term newborns with no apparent hemolysis. The problem is that predicting, recognizing, following up, and the early treatment of jaundice is difficult due to early discharge from hospital and lack of compliance by poor parents. Also, some of them might not attend for follow up and might be missed or uncontrolled. There are conflicting reports about the usefulness of measuring bilirubin level in cord blood in order to predict hyperbilirubinemia in newborns. Nevertheless, most agree about the value of measuring this parameter $(6,10,12-14)$. Thus we can implement this simple bilirubin predicting method before bilirubin level reaches critical levels.

Our study was undertaken to determine prospectively the critical cord serum bilirubin level in order to predict hyperbilirubinemia in healthy term newborns. A cord bilirubin level $\geq 2.25 \mathrm{mg} / \mathrm{dL}$ predicts development of hyperbilirubinemia (define as TCB $\geq 15 \mathrm{mg} / \mathrm{dL}$ ) with sensitivity of $92.6 \%$ at 72 hours of age. In the present study, we excluded many newborns for several reasons, including $\mathrm{ABO} / \mathrm{RH}$ incompatibility, G6PD deficiency; preterm, late preterm, etc; because many studies $(6,15,16)$ have shown these neonates are more likely to develop significant jaundice more than term healthy infants.

The mean total cord bilirubin at birth and TCB at 72 hours of age, had no statistically significant relation to gender and the type of delivery, and consistent with the results of some studies $(10,15,17,18)$. Two studies $(19,20)$ found that UCSB level was significantly different between the sexes. We assume that the difference may be the result of G6PD enzyme deficiency among males as it is an X-linked recessive disorder that was excluded from our study, and they did not exclude these types of babies. The incidence of jaundice is dependent upon ethnic makeup of the population, regional variations, etc. Our study showed $11.4 \%$ of newborns had hyperbilirubinemia and needed photother- apy. These results are not consistent with studies which showed that hyperbilirubinemia occurred in $6 \%$ of infants $(10,13,20)$. This may be due to the fact that they did not follow neonates till the third day of life. On the other hand, Bernaldo and Segre (6) and Zeitoun et al. (15) found that the incidence of jaundice in newborns undergoing phototherapy was significantly higher $(19.86 \%$ and $29.8 \%$ respectively). This could be explained thus that neonates with ABO incompatibility and G6PD deficiency were included in their study.

The mean of UCSB level for babies who received phototherapy was $3.11 \pm 0.72 \mathrm{mg} / \mathrm{dL}$ which is significantly higher than those who did not receive it which was $2.71 \pm$ $0.75 \mathrm{mg} / \mathrm{dL}$. Similarly, Bernaldo and Segre (6), Zeitoun et al. (15) and Taksande et al. (10) found that phototherapy was significantly associated with higher levels of UCSB for infants who received it. Rostami et al. (17), demonstrated that UCSB level $>3 \mathrm{mg} / \mathrm{dL}$ cannot identify newborns with significant jaundice. In comparison to these results, the present study showed that $92.6 \%$ of infants who required phototherapy had UCSB level $\geq 2.25 \mathrm{mg} / \mathrm{dL}$, this is in line with other studies $(6,15)$. Satrya et al. (19) showed that UCSB level $>2.54$ had high specificity and sensitivity. Zeitoun et al. (15) also found that UCSB level $>2.15 \mathrm{mg} / \mathrm{dL}$ had the highest sensitivity and at this critical cord bilirubin level, negative predictive value was very high. However, in our study, UCSB level $<2.25 \mathrm{mg} / \mathrm{dL}$ did not completely exclude the development of significant jaundice; $7.2 \%$ of newborns with $\mathrm{UCSB}<2.25 \mathrm{mg} / \mathrm{dL}$ developed jaundice. Based on our findings, with a critical cutoff level of $2.25 \mathrm{mg}$, UCSB has very high sensitivity which means UCSB level can be used as a reliable screening test to diagnose healthy term infants at risk of hyperbilirubinemia.

Measurement of UCSB level can be used as a screening tool for the development of jaundice requiring intervention therapy. Neonates with UCSB level $\geq 2.25 \mathrm{mg} / \mathrm{dL}$ will need a close follow-up to be checked for the development of jaundice, whereas neonates with UCSB level $<2.25$ $\mathrm{mg} / \mathrm{dL}$ are probably safe for early discharge. We recommend that routine estimation of UCSB level be emphasized in all institutional deliveries to predict the subsequent development of significant jaundice in healthy term newborns.

\section{Footnotes}

Authors' Contribution: Study concept and design: Pedram Niknafs, Bahareh Bahman Bijari, Elaheh Norouzi and Hamid Mosavi. Acquisition of data: Bahareh Bahman Bijari, Zahra Jamali and Maryam Mohit. Analysis and interpretation of data: Mohammad Reza Baneshi, Bahareh Bahman Bijari and Zahra Jamali, Drafting of manuscript: 
Zahra Jamali, Bahareh Bahman Bijari and Mohammad Reza Baneshi. Critical revision of the manuscript for important intellectual content: Zahra Jamali and Bahareh Bahman Bijari. Statistical analysis: Mohammad Reza Baneshi and Zahra Jamali. Administrative, technical and material support: Habibeh Amiresmaeili, Maryam Mohit, Zahra Shahriari and Zahra Jamali. Study supervision: Bahareh Bahman Bijari and Zahra Jamali.

Conflict of Interests: The authors declare no conflict of interest.

\section{Ethical Approval: IR.KMU.REC.1394.562.}

Funding/Support: This study was supported in part by grant 94/536 from Kerman Medical University (Research Center).

\section{References}

1. Alpay F, Sarici SU, Tosuncuk HD, Serdar MA, Inanc N, Gokcay E. The value of first-day bilirubin measurement in predicting the development of significant hyperbilirubinemia in healthy term newborns. Pediatrics. 2000;106(2). E16. doi: 10.1542/peds.106.2.e16. [PubMed: 10920172].

2. Escobar GJ, Greene JD, Hulac P, Kincannon E, Bischoff K, Gardner MN, et al. Rehospitalisation after birth hospitalisation: Patterns among infants of all gestations. Arch Dis Child. 2005;90(2):125-31 doi: 10.1136/adc.2003.039974. [PubMed: 15665162]. [PubMed Central: PMC1720242].

3. Tan-Dy C, Moore A, Satodia P, Blaser S, Fallagh S. Predicting kernicterus in severe unconjugated hyperbilirubinemia. Paediatr Child Health 2004;9(suppl_a):17A.doi:10.1093/pch/9.suppl_a.17a.

4. Alizadeh Ghamsari A, Mohamadzadeh A, Khodadadi A, Rezaei M. Does umbilical cord bilirubin level have predictive value in pathologic neonatal hyperbilirubinemia? Iran J Neonatol. 2013;4(1):32-5.

5. Maisels MJ, Newman TB. Kernicterus in otherwise healthy, breast-fed term newborns. Pediatrics. 1995;96(4 Pt 1):730-3. [PubMed: 7567339].

6. Bernaldo AJ, Segre CA. Bilirubin dosage in cord blood: Could it predict neonatal hyperbilirubinemia? Sao Paulo Med J. 2004;122(3):99103. [PubMed: 15448807]

7. Eggert LD, Wiedmeier SE, Wilson J, Christensen RD. The effect of instituting a prehospital-discharge newborn bilirubin screening program in an 18-hospital health system. Pediatrics. 2006;117(5):e855-62. doi:10.1542/peds.2005-1338. [PubMed: 16651290].
8. American Academy of Pediatrics Subcommittee on Hyperbilirubinemia. Management of hyperbilirubinemia in the newborn infant 35 or more weeks of gestation. Pediatrics. 2004;114(1):297-316. doi: 10.1542/peds.114.1.297. [PubMed: 15231951].

9. Brodersen R. Aqueous solubility, albumin binding, and tissue distribution of bilirubin. New York, NY: Marcel Dekker;1986. p. 157-81.

10. Taksande A, Vilhekar K, Jain M, Zade P, Atkari S, Verkey S. Prediction of the development of neonatal hyperbilirubinemia by increased umbilical cord blood bilirubin. Curr Pediatr Res. 2005;9(1):5-9.

11. Martin R, Fanaroff A, Walash M. Fanaroff and Martin's neonatalperinatal medicine. 10th ed. Philadelphia: Elsevier Health Sciences; 2015. p. 1625-55.

12. Romagnoli C, Tiberi E, Barone G, Curtis MD, Regoli D, Paolillo P, et al. Development and validation of serum bilirubin nomogram to predict the absence of risk for severe hyperbilirubinaemia before discharge: a prospective, multicenter study. Ital J Pediatr. 2012;38:6. doi: 10.1186/1824-7288-38-6. [PubMed: 22296875]. [PubMed Central: PMC3298708]

13. Sun G, Wang YL, Liang JF, Du LZ. [Predictive value of umbilical cord blood bilirubin level for subsequent neonatal jaundice]. Zhonghua Er Ke Za Zhi. 2007;45(11):848-52. Chinese. [PubMed: 18282419].

14. Riskin A, Abend-Weinger M, Bader D. How accurate are neonatologists in identifying clinical jaundice in newborns? Clin Pediatr (Phila). 2003;42(2):153-8. doi: 10.1177/000992280304200209. [PubMed: 12659389].

15. Zeitoun AA, Elhagrasy HF, Abdelsatar DM. Predictive value of umbilical cord blood bilirubin in neonatal hyperbilirubinemia. Egypt Pediatr Assoc Gazette. 2013;61(1):23-30. doi: 10.1016/j.epag.2013.04.006.

16. Selimuzzaman SM, Mitra U, Dey SK, Mannan A, Shahidullah M, Nahar Z. The value of umbilical cord blood bilirubin measurement in predicting the development of significant hyperbilirubinemia in healthy newborn. Bangladesh J Child Health. 1970;33(2):50-4. doi: 10.3329/bjch.v33i2.5677.

17. Rostami N, Mehrabi YE, Asadzadeh F. Identifying the newborns at risk for developing significant hyperbilirubinemia by measuring cord bilirubin levels. Pejouhandeh. 2005;6(42):365-9.

18. Chary E, Bharadwaj N, Kumar P, Vivekand N, Sailaja V, Harika B. Umbilical cord blood bilirubin level measurement in predicting the development of significant hyperbilirubinemia. India JMednodent Allied Sci. 2014;2(2):144. doi: 10.5958/2347-6206.2014.00003.x.

19. Satrya R, Effendi SH, Gumida DA. Correlation between cord blood bilirubin level and incidence of hyperbilirubinemia in term newborns. Paediatrica Indonesiana. 2009;49(6):349-54. doi: 10.14238/pi49.6.2009.349-54.

20. Gatea S. Cord bilirubin level as predictor for newborns at risk for post natal hyperbiliruinemia. Kufa Med J. 2009;12(2):109-17. 